\title{
IDI/ BERGMILLER/ GOEBEL - UMA ESCOLA DE DESIGN: OU UM LABORATÓRIO AVANÇADO DA ESDI
}

Isabella Perrotta ${ }^{1}$

Resumo: O artigo trata da Importância do IDI - Instituto de Desenho Industrial do Museu de Arte Moderna do Rio de Janeiro, muito ativo entre o final da década de 1960 e o final da década de 1970, como uma frente de pesquisa aplicada ao design. Embora completamente desvinculado, institucionalmente, da Escola Superior de Desenho Industrial - ESDI, podese entendê-lo como uma extensão da mesma, uma vez que era um laboratório da metodologia racionalista implantada naquela escola, e coordenado por professores da mesma - como Karl Heinz Bergmiller e Gustavo Goebel Weyne -, além de ter contado com a colaboração de diversos ex-alunos da mesma instituição. $O$ artigo é um primeiro produto do projeto Banco de história oral do design brasileiro: Memória da institucionalização de uma profissão ${ }^{2}$ que tem como objetivo preservar a memória, e colaborar com a construção da história, do design brasileiro.

Palavras-chave: Instituto de Desenho Industrial do MAM RJ / Bergmiller / Goebel

\begin{abstract}
The article is about the importance of Industrial Design Institute of the Museum of Modern Art of Rio de Janeiro - very active between the late 1960's and the late 1970's - as a research front applied to the design and as a laboratory of the rationalist methodology implemented in the School of Industrial Design - ESDI by teachers like Karl Heinz Bergmiller and Gustavo Goebel Weyne. The article is a first product of a project that aims to preserve the memory, and collaborate with the construction of the history, of Brazilian design.
\end{abstract}

Keywords: Industrial Design Institute of Museum of Modern Art of Rio de Janeiro / Bergmiller / Goebel

\footnotetext{
${ }^{1}$ Designer, Doutora em História pela FGV, líder da linha em Design de Experiência e Estratégia de Inovação do Mestrado Profissional em Gestão da Economia Criativa da ESPM Rio.

2 O referido projeto está sendo desenvolvido para ESPM Rio.
} 


\section{INTRODUÇÃO}

No Brasil, a institucionalização da profissão do designer começa a se dar, em São Paulo e no Rio de Janeiro, entre as décadas de 1950 e 1960. Os dois principais centros culturais, políticos e econômicos do país na época, ensaiaram os primeiros movimentos para a formação de um profissional criativo e capacitado a desenvolver produtos industriais e mensagens visuais passíveis de serem transmitidas em série. As duas cidades desenharam um percurso parecido, no que diz respeito a absorção de influências do design internacional, mas adaptaram-se a realidades internas um pouco diferentes.

Duas mulheres progressistas e dois museus estruturados em torno de um projeto de atuação didática foram personagens importantes do início dessas histórias. Em São Paulo, a arquiteta italiana Lina Bo Bardi (em parceria com seu marido - o crítico e marchand - Pietro Maria Bardi) e, no Rio, a jornalista baiana Niomar Muniz Sodré Bittencourt. Em São Paulo, o MASP - Museu de Arte de São Paulo; no Rio, o MAM - Museu de Arte Moderna.

Lina, ligada ao MASP, participou da criação do primeiro curso de arte voltado aos princípios do design moderno, editou a revista Habitat que divulgava projetos de arquitetura e design com estética moderna e viés funcionalista, foi autora de importantes obras arquitetônicas do país (como o próprio MASP) e também dos primeiros móveis modernos brasileiros. Niomar foi jornalista e intelectual de circulação internacional, muito atuante no combate à ditadura militar, principalmente quando esteve à frente do jornal Correio da Manhã, e diretora do Museu de Arte Moderna do Rio de Janeiro (então da Guanabara), dando-Ihe cunho educativo e abrindo-o para o design.

O MASP foi fundado em 1947, por iniciativa do empresário Assis Chateaubriand, tendo como sede uma sala da sua empresa, os Diários Associados. Em 1950, passou a ocupar quatro andares do mesmo edifício, dando início à sua atuação didática, área na qual se notabilizou, sendo um dos primeiros museus do continente a atuar com o perfil de centro cultural. Em 1951 o museu cria o Instituto de Arte Contemporânea - IAC, idealizado por Lina Bo Bardi, Pietro Maria Bardi e o arquiteto Jacob Rucht, com o objetivo de formar jovens profissionais para trabalhar com "arte industrial" que fossem "capazes de desenhar objetos nos quais o gosto e a racionalidade das formas correspond[essem] ao progresso e à mentalidade atualizada" (Folheto de divulgação do Instituto, 1950). Desde 1968, passou a funcionar em edifício projetado por Lina Bo Bardi, na avenida Paulista.

O MAM do Rio de Janeiro foi instituído em 1948, por iniciativa de um grupo de empresários presidido por Raymundo Ottoni de Castro Maya. Em 1952 foi instalado provisoriamente no icônico prédio modernista do Palácio da Cultura, e em dezembro do mesmo ano a Câmara dos Vereadores aprova a doação, para a instituição, de um terreno de 40 mil metros quadrados no Aterro do Flamengo. A transferência para a sede própria, com projeto do arquiteto Affonso Eduardo Reidy, se deu em 1958, com a inauguração do Bloco Escola, sendo o prédio principal, de exposições, inaugurado em 1963. 


\section{DE ULM AO RIO}

Em 1956 as sementes do design começam a ser plantadas no MAM (em meio a plantas tropicais e desenhos concretistas dos jardins de Burle Max...). Neste ano, Niomar Muniz Sodré encontra-se, na Europa, com Max Bill - primeiro diretor da Escola da Forma de $\mathrm{Ulm}^{3}$ (instituição de forte caráter racionalista, funcionalista e industrialista, fundada na Alemanha em 1953) -, e este lhe propõe criar um curso de design no museu. Bill já tinha algum contato com o Brasil desde a sua participação com premiação e muito sucesso - na I Bienal de Artes de São Paulo, em 1951; e pelo fato de, nestas alturas, alguns brasileiros já terem passado pela escola de Ulm (tanto no curso de design, como no de arquitetura). Ele também já tinha voltado ao Brasil em 1953, quando proferiu a polêmica conferência "O arquiteto, a arquitetura e a sociedade", no MAM do Rio e na FAUUSP, fazendo duras críticas à arquitetura brasileira que, para ele, padecia do "amor ao inútil, ao simplesmente decorativo", e aos seus principais representantes - Lúcio Costa e Niemeyer: “(...) vosso país está em perigo de cair no mais terrível academicismo anti-social no plano da arquitetura moderna" (Habitat, no 14, Jan./Fev. 1954).

Também em 1956, Niomar encontra-se, no Brasil, com Tomás Maldonado - que já substituíra Bill na direção da escola alemã, imprimindo uma proposta de ensino menos artística e mais tecnológica. Maldonado representava o grupo de artistas concretistas argentino e já tinha participado de uma exposição no Rio em 1953, quando também proferiu palestras sobre arte abstrata. O encontro com Niomar deuse quando ele acompanhava os artistas do Grupo Frente (de cariocas neoconcretos) em exposição, patrocinada pelo MAM, na Companhia Siderúrgica Nacional de Volta Redonda - já que o grupo trabalhava para levar sua arte para o interior do estado (CUNHA, 1994).

Neste encontro, Niomar solicita a Maldonado um planejamento para uma "escola de projetos" para o MAM. Embora a proposta da Escola Técnica de Criação não tenha se concretizado, serviria de base para a constituição da ESDI - Escola Superior de Desenho Industrial, (fundada em 1962, e tida como a primeira escola de nível superior da matéria na America Latina), além de ter fomentado a iniciativa do museu de abrigar uma série de palestras, cursos e encontros com personalidades do design, e exposições internacionais sobre o tema.

Cita-se pelo menos dois cursos relevantes acontecidos no MAM antes da fundação da ESDI: em 1959, um curso de comunicação visual ministrado por Otl Aicher (designer alemão idealizador da Escola da Forma de Ulm) e Tomás Maldonado, que teve entre seus alunos Gustavo Goebel Weyne; e, em 1962, um sobre tipografia, tendo Aloísio Magalhães e Alexandre Wollner como professores.

Não por acaso, Goebel, Aloísio, Wollner, e ainda (ou principalmente) Karl Heinz Bergmiller foram os quatro designers e professores mais importantes na definição do perfil pedagógico da ESDI e da criação de uma cultura esdiana. Aloísio, Wollner e Bergmiller desde a formatação do projeto de criação da Escola, e Goebel, desde o início do curso.

O pernambucano Aloísio Magalhães foi artista plástico, gráfico amador, designer, secretário de cultura e diretor do Instituto do Patrimônio Histórico e Artístico Nacional, tendo obtido projeção internacional.

\footnotetext{
${ }^{3}$ Em alemão, Hochschule für Gestaltung (HfG).
} 
O paulistano Alexandre Wollner foi pintor concretista, participou de cursos do IAC do MASP, de 1951 a 53, e trabalhou em montagens de exposições no mesmo museu, onde teve oportunidade de conhecer Max Bill e ser indicado para estudar em Ulm, onde frequentou o departamento de comunicação visual, de 1955 a 58.

O cearense Gustavo Goebel Weyne, participou do grupo de artistas concretistas do seu estado; em São Paulo, frequentou informalmente aulas no IAC do MASP (onde conheceu Wollner) e começou a trabalhar com design gráfico de revistas. Posteriormente, no Rio, diagrama a revista Módulo, editada por Oscar Niemeyer.

O alemão Karl Heinz Bergmiller Bergmiller, diferentemente dos outros, não tinha relação com as artes plásticas. Ao contrario, foi pela sua experiência com tecnologia e indústria, em sua cidade natal - perto de UIm -, que decide frequentar o curso de design industrial na escola que se intitulava herdeira da Bauhaus ${ }^{4}$.

Ulm abrigava uma "colônia de brasileiros", com a qual Bergmiller teve contato: Alexandre Wollner, Almir Mavignier, Mary Vieira e as irmãs Frauke e Elke Koch-Weser, entre outros - num total de dez ${ }^{5}$, que por lá passaram. Destes citados por Karl Heinz, apenas Wollner retornou ao Brasil e, de certa forma, foi o responsável pela migração do seu colega alemão. Para Bergmiller, o Brasil era uma possibilidade entre outras - o desejo era emigrar para qualquer lugar, vistas as condições da Alemanha pós guerra ${ }^{6}$. Mas, sim, o Brasil desenvolvimentista de JK e Brasília ${ }^{7}$ chamava a sua atenção...

Niomar (e o seu projeto da futura escola para o museu) também se relaciona com a história de Wollner em Ulm. Quando postulante ao curso na Alemanha sabendo da influência da jornalista no meio diplomático brasileiro - Wollner a procura para conseguir subsídios para sua viagem, estabelecendo, então, um certo compromisso de ajudá-la a formatar o curso de design do MAM. E, regressando, é a vinda de Bergmiller para o Brasil que Wollner ajuda a articular junto ao Itamaraty.

\section{A ESDI}

A ideia de uma escola de Desenho Industrial de nível superior, no então Estado da Guanabara, partiu do secretário de Educação e Cultura - Carlos Flexa Ribeiro durante o governo de Carlos Lacerda. O objetivo era formar profissionais para atender "às exigências da nossa sociedade industrial" e ao "surto industrial de nosso país". Assim, em 1962, foi nomeada uma comissão inicial de planejamento do curso e, em julho de 1963, a Escola começou a funcionar, após o primeiro processo de seleção de candidatos.

Numa primeira fase, participaram do projeto de elaboração do curso Lamartine Oberg, Maurício Roberto (primeiro diretor) e Wladimir Alves de Souza, organizando o primeiro currículo básico, que foi posteriormente modificado com a inclusão nesta comissão de Joseph Carreiro, diretor do Departamento de Industrial Design do Philadelphia Museum College of Art (escola onde Aloísio Magalhães havia atuado como professor). E uma nova estrutura foi concebida após a participação de Karl Heinz Bergmiller, Alexandre Wollner, Aloísio Magalhães e Orlando Luiz de Souza Costa.

\footnotetext{
${ }^{4}$ BERGMILLER. Depoimento para a autora em 10/3/2016.

${ }^{5}$ CUNHA, 1994.

${ }^{6}$ BERGMILLER. Depoimento para a autora em 10/3/2016.

${ }^{7}$ Cartazes com a temática Brasília aparecem no portfólio de trabalhos de Almir Mavignier e Mary Vieira nos tempos de Ulm, o que demonstra a repercussão deste projeto na Europa.
} 
Também tiveram alguma participado nas reuniões da comissão José Simeão Leal, Flávio d'Aquino (que substituirá Mauricio Roberto na direção), Euryalo Cannabrava, Robin Darwin e Mischa Black, estes dois últimos do Royal College of Art.

Apesar do surto industrial de nosso país, a forma dos nossos produtos ainda é de inspiração estrangeira, pagando-se "royalties" por suas patentes importadas ou improvisando-se "variantes" das mesmas. No setor do equipamento da habitação, quase todo baseado na dispendiosa produção artesanal, o objeto de boa forma é de uso exclusivo de um pequeno grupo social de grande poder aquisitivo. O campo da Comunicação Visual, de maneira geral, está dominado pelo amadorismo e pelo excesso de comercialismo, sentindo-se a necessidade premente de estabelecimentos educacionais destinados a formar profissionais competentes. Impunha-se, assim, a criação de uma Escola de Desenho Industrial, de nível superior, que pudesse lutar contra o marginalismo da profissão e que - como única no gênero em nosso país - tivesse âmbito nacional, não se limitando seu campo de ação apenas ao Estado da Guanabara. A Escola Superior de Desenho Industrial tem por objetivo formar - através de uma educação técnica, científica, artística, e cultural - profissionais de nível universitário que possam atender as duas exigências de nossa sociedade industrial: planejamento de produtos industriais (Industrial Design) e planejamento de meios de Comunicação Visual (Graphic Design). Dois órgãos colaboram na consecução dessas finalidades: a Comissão de Assessoria e o Centro de Pesquisas. Através do primeiro, a ESDI entrosa-se com a realidade de nossa indústria e da nossa criação artística, pelo contato constante e direto com seus representantes. Por meio do Centro de Pesquisas, alunos e professores, trabalhando em equipe, planejam e solucionam problemas concretos referentes ao Desenho Industrial e à Comunicação Visual, que the forem enviados por órgãos estatais ou entidades privadas. A criação do CP tem ainda por finalidade permitir que alunos e professores dediquem-se inteiramente à pesquisa e ao ensino, sem prejuízo de sua economia privada. 0 Centro não tem intenção de concorrer com as empresas ou escritórios particulares que se ocupem do ramo, aos quais, inclusive, pode ajudar com soluções técnicas ou com a elaboração de maquetas e protótipos em suas oficinas. (Folder da Escola Superior de Desenho Industrial, c. anos 1960).

Mas o fato do projeto de uma escola de design, para o estado, ter abandonado o seu berço original (no MAM), não ficou despercebido.

As coisas acontecem no Brasil da maneira mais absurda possível. O exemplo mais recente é a ESDI. O governo tem dinheiro, mas não tem escola. O MAM tem a escola mas não tem dinheiro. Em vez de uma aliança para o progresso o governo adapta um prédio velho onde funcionará mal instalada a escola e o MAM continuará a funcionar mal num prédio especialmente construído para ser uma escola da forma industrial. Quem poderá garantir que a Escola vá adiante se o curso é de quatro anos e começará em $64^{8}$ com instalações com instalações apenas para o primeiro. Se Jânio Quadros paralisou as obras de Brasília, porque um governador não poderá fazer o mesmo com uma escola?

\footnotetext{
${ }^{8}$ A Escola começou a funcionar no segundo semestre de 1963.
} 
(Harry Laus9, "Museu, governo e desenho industrial", Jornal do Brasil, 30/4/1963, apud SOUZA, 1996 p.17).

Difícil dizer se a escola do MAM seria melhor, mas - pelo menos - podemos afirmar a longevidade da ESDI, hoje com mais de 50 anos, ultrapassando em muito as histórias da Bauhaus e da Escola da Forma de Ulm.

\section{IDI: LABORATÓRIO DIDÁTICO}

Em 1959, a caminho de São Paulo - onde trabalharia com o colega Alexandre Wollner -, Bergmiller desembarca (por algumas horas), no porto do Rio. Ele atravessa a pé o corredor da avenida Rio Branco, alcançando sua outra extremidade, onde avista o Museu da Arte Moderna, com o Pão de Açúcar ao fundo. A paisagem com o prédio do museu - cujo projeto arquitetônico já conhecia - encanta, mas naquele momento, não poderia imaginar que um dia atuaria profissionalmente ali ${ }^{10}$.

Foi neste museu - que desde seus primeiros momentos incluiu o design em seus planos - que funcionou um verdadeiro laboratório de pesquisa aplicada na área do design, atendendo, principalmente, a instituições públicas.

O IDI - Instituto de Desenho Industrial começa a nascer em 1968, quando o Museu de Arte Moderna do Rio de Janeiro sediou a primeira Bienal Internacional de Design ${ }^{11}$, durou pouco mais de dez anos, e começou a acabar com o incêndio do museu, em 1978.

A mostra - intitulada Desenho Industrial 68 Bienal Internacional do Rio de Janeiro - foi uma iniciativa do Ministério das Relações Internacionais, com a participações da ESDI, da FAUUSP e da Fiesp entre outras entidades.

Contudo, antes deste evento, o arquiteto Maurício Roberto - primeiro diretor da ESDI e então diretor do MAM - já havia convidado o designer alemão Karl Heinz Bergmiller (que conhecera desde os primeiros momentos da constituição da Escola) para projetar o sistema expositivo do museu, assim como o planejamento de montagem das exposições que lá ocorriam. E assim aconteceu também na Bienal de Design, quando Bergmiller teve a parceria do colega (professor da ESDI) e designer Gustavo Goebel Weyne na parte gráfica da mostra, que incluiu a representação de três países estrangeiros (Estados Unidos, Canadá e Inglaterra ${ }^{12}$ - por causa da identidade do idioma), e as áreas gráfica e de produto.

Desenho Industrial 68 foi uma mostra essencialmente didática que colocou em termos de conceituação e de aplicação prática uma abordagem da atividade design. A exposição foi planejada como um todo, o que permitiu que fosse dado o mesmo tratamento às diversas partes que integravam a mostra (SOUZA E STEIMBERG, 1978, s/p.).

A partir deste evento, pensou-se em criar uma divisão de design dentro do museu - que, de certa forma, tinha sido prevista desde a sua criação (como escola). 0

\footnotetext{
${ }^{9}$ Crítico de arte e escritor brasileiro.

${ }^{10}$ BERGMILLER. Depoimento para a autora em 10/3/2016.

${ }^{11}$ Existiram, na mesma instituição, a segunda e a terceira bienal, em 1970 e 1972.

12 Nas edições subsequentes da Bienal, a participação estrangeira foi representada por Dinamarca,

Finlândia Noruega e Suíça, em 1970, e Alemanha e Suíça, em 1972.
} 
IDI - Instituto de Desenho Industrial foi pensado por Bergmiller e Goebel (professores da ESDI), coordenado pelos mesmos e, posteriormente, também por Pedro Luiz Pereira de Souza e Silvia Steimberg (ex-alunos e futuros professores da mesma escola). Foi frente de pesquisas aplicadas do design. Praticamente um laboratório avançado da ESDI, posto que colocava em prática os preceitos ensinados na escola, além de divulgar didaticamente a profissão. Foi um celeiro da metodologia ulmiana - que Wollner e Bergmiller literalmente brigaram para implantar na ESDI ${ }^{13}$ (em oposição a alguns outros membros do grupo de trabalho de formação da escola), e que foi reforçada com a inclusão, no corpo docente da Escola, em 1964, do suíço Paul Edgard Decurtins (também oriundo de Ulm).

Ao longo de sua existência, o IDI desenvolveu trabalhos de modo sistemático, nas quatro áreas em que estava organizado: Desenvolvimento de Projeto, Exposições, Informação e Consultoria. Mesmo na produção da área Desenvolvimento de Projeto fica evidente a preocupação do Instituto com a "responsabilidade" didática que tomou para si. Seus principais projetos foram normativos. Referências e diretrizes para projetos futuros de todo uma geração profissional que se formava.

Não há design de laboratório, desligado da prática da produção. Sendo ainda um trabalho interdisciplinar, ele corre o risco de se tornar indisciplinado e em seu nome serem levantadas divagações e derivações de outras atividades arvoradas em pesquisa. (SOUZA e STEIMBERG, 1978, s/p.).

Como exemplo de projetos normativos, os dois mais importantes produtos do IDI foram: o Manual para planejamento de embalagens, editado em 1976, abordando conceitos, normas, materiais, processos gráficos e de produção, comunicação visual, mercadologia, planejamento e projetos didáticos exemplificando a aplicação do método de trabalho proposto; e o Móvel escolar, que não é "simplesmente" um projeto definido por desenhos de fabricação, mas por um trabalho de racionalização de aspectos de uso e produção deste equipamento, objetivando definir critérios orientadores para os setores envolvidos com a compra, uso e produção do mobiliário escolar. Instituto,

As próprias bienais de design, entre outras exposições promovidas pelo "foram importantes referências para os trabalhos de divulgação e democratização da informação sobre o design, bastante escassas nessa época" (idem).

Bergmiller é didático como professor ou profissional. Segundo ele, "o trabalho do designer não é fazer pés de mesa, mas cabeças de empresários" ${ }^{14}$. Talvez venha daí a cultura do designer brasileiro de acreditar que devemos sempre explicar o que fazemos porque, afinal, "nem a minha mãe entende o que eu faço ${ }^{15}$..."

profissional,

Quando convidado a gravar um depoimento ${ }^{16}$ sobre a sua trajetória Bergmiller preferiu não falar de um (ou alguns) de seus muitos projetos de produtos bem sucedidos, mas de um projeto didático que começou com a sua recusa em aceitar

\footnotetext{
${ }^{13}$ WOLLNER (2003).

${ }^{14}$ BERGMILLER. Depoimento para a autora em 10/3/2016.

${ }^{15}$ Bordão da profissão.

16 Para esta autora.
} 
um determinado trabalho profissional. E didático foram o tema e o tom do seu depoimento.

O início da história é o ano de 1960, com um empresário demonstrando uma postura "incompatível" com seu perfil profissional, e ela foi retomada 10 anos mais tarde, quando o designer teve a chance de rever o mesmo tema com enfoque diferente, e sem a participação de qualquer cliente.

Em 1960, então, Karl Heinz foi chamado para desenhar um estojo de talheres (desses faqueiros forrados de veludo...). Quando o fabricante colocou os talheres sobre a mesa, Bergmiller fez cara de que não gostou. O cliente argumentou - batendo na mesa - que tinha outro tipo de coisa lá fora, mas que o que o brasileiro gostava mesmo era aquilo. Ele não se lembra ao certo, mas acredita ter pensado: "um dia vou mostrar o que o brasileiro gostaria de ter na sua mesa de jantar".

Assim, em 1970, com a Exposição internacional de talher contemporâneo, realizada no MAM, pelo IDI, ele pode fazer o pretendido - "Ao final da exposição, pudemos mostrar que o que tinha lá fora era o que o brasileiro gostaria de ter". E, "a exposição foi muito mais importante do que um projetinho de estojo" ${ }^{17}$.

O projeto da exposição começou com uma grande pesquisa em revistas, catálogos e livros que selecionou 71 modelos de nove países. Depois, os contatos com as representações diplomáticas para onde foram enviados as especificações de modelos e fabricantes. As embaixadas entenderam o projeto e os fabricantes estrangeiros a sua importância. O Brasil foi representado com "três modelos interessantes" - em especial pelo talher de camping desenhado por Bornancini (que está no acervo do MoMA) e por um outro de uma companhia aérea.

A exposição circulou em outras capitais do país, com as vitrines desenhadas e fabricadas no próprio MAM (cujas oficinas tinham sido pensadas para abrigar uma escola de design).

O público adorou e ficou frustrado de não poder comprar. A imprensa teve boa reação e, em São Paulo, publicou a manchete "Jogue fora o talher da sua avó" - como se fosse o seu próprio desabafo àquele empresário que o tinha procurado 10 anos antes.

Bergmiller acredita que "o empresário é acomodado por que o consumidor é mal informado", por isso no IDI "levantamos uma serie de temas que podiam melhorar a consciência da produção".

Bergmiller trouxe para a gravação do seu depoimento os talheres que usa na sua casa: "Há 50 anos comendo, lavando, comendo, lavando... o mesmo talher. É qualidade!" Tal talher foi o trabalho de final de curso (em Ulm) de seu colega Ernst Moeckl. "Um funcionalista fanático que martelou, limou, lixou por 30 a 40 dias".

O mestre chama a tenção para o fato de uma colher ser uma ferramenta como uma chave de fenda - que tem um lado da mão e um lado da ação. Os dois lados tem que estar bem resolvidos. E mais uma vez, expõe sua veia didática: "só se pode falar de design num país que tem a consciência de ensinar a profissão" - numa clara referência à ESDI - escola que ajudou a projetar, e onde lecionou, e que teve no IDI uma extensão. Um laboratório para seus alunos e professores.

O IDI manteve uma equipe permanente de coordenação (já citada) mas, para cada projeto desenvolvido, agregava ao grupo novos profissionais - da área de design ou de outras expertises -, de acordo com a especificidade de cada trabalho. Entre os

\footnotetext{
${ }^{17}$ BERGMILLER. Depoimento para a autora em 10/3/2016.
} 
designers atuantes em projetos diversos estiveram Aloísio Magalhães, e os ex-alunos da ESDI Freddy van Camp, Gláucio Campelo, Luiz Alberto Zuniga, Maria Beatriz Afflalo Brandão e Washington Lessa (quase todos, depois professores). Não designers, mas também professores da Escola - Décio Pignatari e Zuenir Ventura - também colaboraram com o Instituto. Tudo isso reforça o caráter pedagógico do IDI e sua estreita ligação com a ESDI.

\section{CONCLUSÃO}

Se Wollner e Bergmiller lutaram para que a ESDI seguisse as diretrizes pedagógicas da escola de Ulm as mesmas foram, aos poucos, sendo criticadas pelos diretores que se sucediam - Flávio de Aquino e Carmem Portinho - assim como pelos professores de vertente menos racionalista - como Renina Katz - e pelos próprios alunos $^{18}$. No entanto, o ulmianismo e seus princípios formalistas e racionais foram mantidos, de certa forma, no percurso do IDI e, mais do que isso, perpetuados em trabalhos que se tornaram referências para a categoria profissional.

Segundo Pedro Luiz Pereira de Souza, na ESDI a crença maior era na racionalidade - não exatamente no industrialismo. Isso se exemplifica no fato dos projetos do IDI não terem sido produtos acabados e produzidos industrialmente mas, em geral, desenvolvidos para o setor público. E exatamente isso viria a ser um problema de sobrevivência para o Instituto, que tinha como uma de suas dificuldades o próprio MAM - que sempre dependeu do poder público, ao mesmo tempo que queria manter sua autonomia como entidade particular ${ }^{19}$. Essa critica - mais de Pedro do que de Bergmiller - mostra um contraponto de personalidades e ideologias na orientação do IDI, apesar do forte caráter formalista ser uníssono.

Formalismo traduzido em capacidade de síntese e racionalidade, assim como a responsabilidade didática perante a sociedade, são características constantemente citadas pelos pupilos de Bergmiller e Goebel $^{20}$ que, de alguma forma, continuam retransmitindo-as para seus clientes, para suas equipes de trabalho, para seus alunos, para futuras gerações que talvez nunca venham a ouvir falar do IDI e destes profissionais que criaram uma cultura para o design brasileiro. Mas a cultura ficou e ficará.

Embora o IDI seja mais associado a Bergmiller, temos que reconhecer que se o Instituto teve (ou ainda tem, nos registros de seus projetos) "uma cara", esta foi de responsabilidade de Goebel Weyne, designer gráfico parceiro de Karl Heinz Bergmiller em várias empreitadas profissionais também fora do MAM, como a da Escriba empresa de móveis profissionais.

Assim, o legado de Goebel ainda merece ser compilado e estudado. Infelizmente, ele nos deixou antes que começasse a nossa iniciativa de gravação de depoimentos para o projeto Banco de história oral do design brasileiro: Memória da institucionalização de uma profissão.

\footnotetext{
${ }^{18}$ WOLLNER (2003).

${ }^{19}$ SOUZA, depoimento para a autora em 15/7/2015.

${ }^{20}$ Ainda em outros depoimentos para a autora.
} 


\section{REFERÊNCIAS}

BERGMILLER, Karl Heinz. Depoimento colhido em 10/3/2016.

BILL, Max. "O arquiteto, a arquitetura e a sociedade", in revista Habitat No. 14. São Paulo, Jan./Fev., 1954.

CUNHA, Eileen M.F. "O Grupo Frente e o experimentalismo emergente de Lygia Pape, Lygia Clark e Helio Oiticica" in Artes e Ensaios, revista do Mestrado em História da Arte, EBA-UFRJ. 1(1), 10 semestre, 1994.

Folheto de divulgação do Instituto de Arte Contemporânea do Museu de Arte de São Paulo. 1950.

NOBRE, Ana Luiza de Souza. Fios cortantes: Projeto e produto, arquitetura e design no Rio de Janeiro (1950-70). 2008. Tese (Doutorado) - Pontifícia Universidade do Rio de Janeiro, Programa de Pós-Graduação em História Social da Cultura.

SECRETARIA de Educação e Cultura do Estado da Guanabara. Escola Superior de Desenho Industrial [folder de divulgação]. Rio de Janeiro, s/d, anos 1960.

SOUZA , Pedro Luiz Pereira de. Esdi biografia de uma ideia. Rio de Janeiro: UERJ. 1996. SOUZA , Pedro Luiz Pereira de e STEIMBERG, Silvia. IDI [relatório de atividades]. 1978.

SOUZA , Pedro Luiz Pereira de. Depoimento colhido em 15 de julho de 2015.

WOLLNER, Alexandre. Design visual 50 anos. São Paulo: Cosac \& Naif. 2003. 